\title{
Towards Knowledge-based Smart Service Systems: The Case of a Recommender System for a Cultural Organization
}

\author{
Thang Le Dinh ${ }^{1 *}$, Nguyen Anh Khoa Dam ${ }^{1,2}$, and Gia Huan $\mathrm{Ho}^{1}$ \\ ${ }^{1}$ Business School, Université du Québec à Trois-Rivières, Canada \\ 2 The University of Danang, University of Science and Technology, Vietnam
}

\begin{abstract}
Big data and artificial intelligence (AI) lead to a revolution that transforms conventional enterprises into data-driven organizations in which knowledge discovered from big data and processed by AI techniques will be integrated into traditional knowledge in order to provide smart services to business users. Consequently, a major concern is how to design and develop a knowledge-based smart service system for supporting AI-based applications. This paper proposes an approach for elaborating a knowledge-based smart service system and demonstrates the approach with a case study about a knowledge-based smart service system for a cultural organization. The proposed approach includes different layers such as Data-as-a-Service, Information-as-a-Service, Knowledge-as-a-Service, and Insight-as-a-Service.
\end{abstract}

\section{Introduction}

The age of big data has turned the spotlight on artificial intelligence (AI) for smart services [1]. This revolution has transformed conventional enterprises into data-driven organizations, which aim at applying AI techniques to discover knowledge from big data for innovative smart services [2,3]. Service is considered smart in the sense that it is dynamic, context-aware, and interconnected for providing customers with personalized solutions $[4,5]$. A smart service system is a service system, which is capable of learning, dynamic adaptation, and decision-making based upon data received, transmitted, and/or processed to improve its response to a future situation [6]. Consequently, studies related to smart services and smart service systems have been an emerging research direction in several disciplines such as information systems, marketing, computer science, industrial engineering, and business administration [7]. However, designing and deploying a smart service system is still a challenge due to the lack of adequate and appropriate models, frameworks, and approaches, especially for supporting AI-based services [8,9].

Building from these reflections, the objective of the paper is to propose an approach for elaborating a knowledge-based smart service system, including different layers such as Data-as-a-Service, Information-as-a-Service, Knowledge-as-a-Service, and Insight-as-a-

\footnotetext{
* Corresponding author: thang.ledinh@uqtr.ca
} 
Service. The proposed approach is presented and demonstrated based on a case study about a knowledge-based smart service system for a cultural organization, which provides recommendations as a service. The case study focuses on a small and medium-sized cultural organization in the region of Québec, Canada.

The rest of the paper is organized such as the following. Section 2 presents the theoretical background related to organizational knowledge, knowledge development, and big data analytics. Section 3 proposes the approach for elaborating knowledge-based smart service systems and presents different layers of the proposed approach. Section 4 discusses the case study related to a smart service system for providing recommendations as a service. Finally, section 5 ends the paper with conclusions and further research directions.

\section{Theoretical backgrounds}

\subsection{Organisational knowledge}

Organizational knowledge is defined as a subset of which is both true and believed that it is created by social interactions among individuals and organizations [10]. Knowledge is dynamic and context-specific since it depends on a particular time and space [11].

In the context of an organization, there are different forms of knowledge, called knowledge components, including know-what, know-how, know-why, and know-who $[12,13]$. Know-what represents artefacts, which are known and related to a phenomenon of interest. Know-how represents the understanding of the generative processes, which constitute organizational phenomena. Know-why represents the understanding of principles of the underlying phenomena. Know-who represents individuals, groups, or organizations, which use other forms of knowledge.

Knowledge management is defined as the process of creating, confirming, representing, distributing, and applying information and knowledge in the organization in order to ensure organizational success $[14,15]$.

\subsection{Knowledge development}

The data-information-knowledge-wisdom hierarchy (DIKW), also called 'Knowledge Hierarchy' is one of the fundamental and widely recognized models in the domain of knowledge management [16]. Knowledge development can be considered as the process involved in the transformation of an entity at a lower level (e.g. data) to an entity at a higher level in the hierarchy (e.g. information). In other words, data can be used to create information; information can be used to create knowledge, and knowledge can be used to create wisdom [16].

Data are captured and stored inside the organizational research through research, creation, gathering, and discovery. Data are turned into information by adding semantics so that it can be easily used by business users. Knowledge has the complexity of experience, which comes about by organizing it based on different forms of knowledge. Wisdom is the ultimate level of understanding.

\subsection{Big data analytics}

Big data is defined as datasets, whose size is beyond the ability of traditional software tools [17], that is generated from mobile phones, network servers, social network, and Internet-of-things [18]. New abilities and tools for big data analysis stimulated decision- 
makers to shift their focus from knowledge back to data as the "oil of the new economy" [18]. Data becomes a key resource for an enterprise to create value and provide competitive advantages [18]. Knowledge discovery through data mining helps enterprises to generate knowledge, which supports the decision-making process that is generated through real-time analysis of all the existing data using automated algorithms [18].

To create value from big data, another emerging concept is datafication of a phenomenon, which refers to the process of putting that phenomenon into a quantified format for tabulation and analysis [18]. Datafication can be considered as a knowledge development process that comprises of three steps [19]:

1. Dematerialization referring to the ability to separate the data aspects of an asset and its use,

2. Liquefaction referring to the manipulation and movement of data for reuse for different purposes, and

3. Density referring to the recombination of resources mobilized for a particular context.

Accordingly, big data analytics has led to reflections on the traditional DIKW hierarchy [20]. Laszlo's pyramid that is enlarged and designated as "the pyramid of meaning" starts with data and moves up to information, from information into knowledge, from knowledge into understanding, and from understanding to wisdom [19]. Information and knowledge can be formally transmitted; however, understanding a situation is unique to each person since it involves active engagement in learning and creating meaning [19]. Consequently, data and information focus on "what" questions, knowledge focuses on "how" questions, and understanding and wisdom focus on "why" questions [19]. In our approach, we limit the scope of the study to the understanding level of the hierarchy that is the "understanding" of knowledge to overcome a specific business situation [20].

\section{Knowledge-based smart service systems}

Big data analytics can create business value in smart service systems and promote smart service system innovation [21]. For instance, customer data may get converted into information, which can be analysed to understand patterns of customer behaviour, to learn why customers make certain decisions or behave in certain ways, and to design new services or improve existing services [21]. Big data analytics can help foster new service innovations, creating smart service systems by embedding organizational knowledge and capabilities in technologies to serve human purposes for effective value co-creation [21]. However, a key challenge in such innovating smart service systems lies in taking advantage of big data analytics to create business value [21].

For this reason, this study aims at proposing an approach for elaborating a knowledge-based smart service system based on the knowledge development process (Fig. $1)$. 


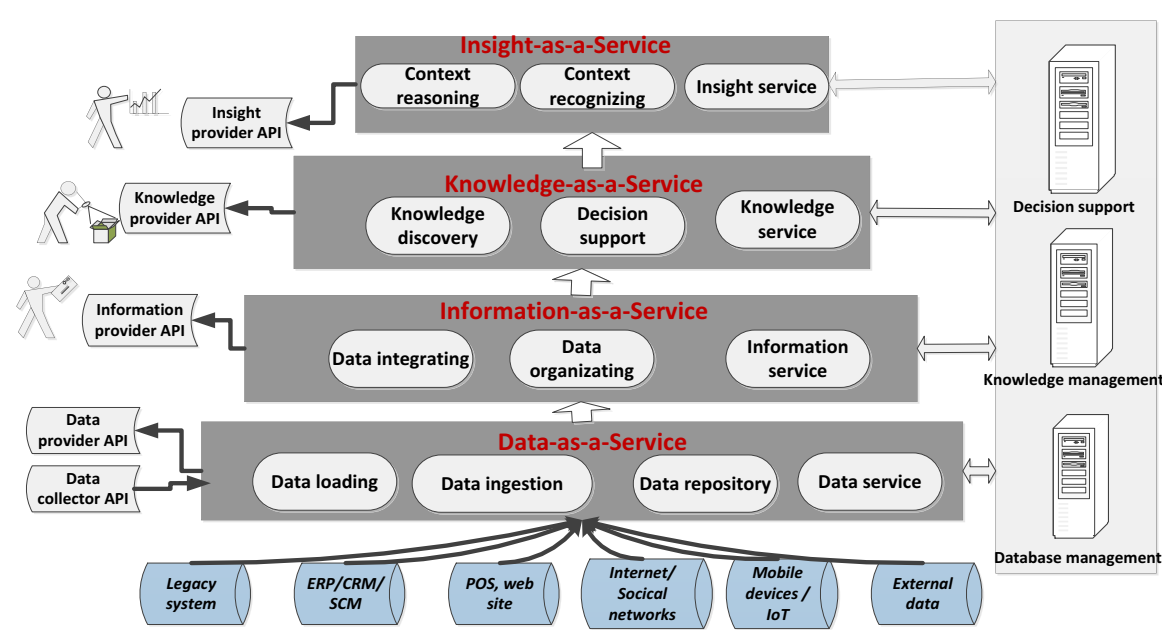

Fig. 1. A knowledge-based smart service system.

The proposed approach for elaborating a knowledge-based smart service system covers different levels of the knowledge process such as Data-as-a-Service for the data level, Information-as-a-Service for the information level, Knowledge-as-a-Service for the knowledge level, and Insight-as-a-Service for the understanding level.

\subsection{Data-as-a-Service}

The data-as-a-Service level aims at dematerialization, which refers to the ability to separate the data aspects of an information asset and its use. This level transforms raw data from different sources to structured data with specific purposes. Data can be acquired from a variety of source systems, including operational/transactional systems, enterprise resource planning (ERP) systems, Customer relationship management (CRM), Web sites, social networks, the Internet of things, and third-party sources [22]. Raw data are captured and processed by different components such as data loading, data ingestion, data repository, and data service.

Data loading retrieves the batch data (both unstructured and structured) into the system's main databases $[23,24]$. Unstructured data contain unordered raw data with a large percentage of noise data that requires training models for data cleaning [25]. Structured data, on the other hand, have their own structure and format and can be loaded into the system without any difficulties assuming that the format of the data and the database inside the system are identical.

Data ingestion gathers and processes raw data (mainly unstructured data), which is processed into structured data based on the system's internal format [26]. In most cases, the data can be loaded through a user-friendly interface on the website given that the user can $\log$ in to the system to upload the data [27].

Data repository aims at storing data in temporary files/storage or database management systems $[28,29]$. Once data are processed and cleaned, the repository can also retrieve the processed backup data.

Data service provides the data requesting services so that users can update data periodically and retrieve their data as they wish. This component provides different Dataas-a-Service such as Data provider API and Data collector API. 


\subsection{Information-as-a-Service}

Information-as-a-Service aims at the liquefaction, which refers to the manipulation and movement of data for reuse for different purposes. This level, which supports the process of processing information to figure out the semantics of data, includes different components such as data integration, data organization, and information service.

Data integration links and integrates data from different sources based on the semantics of data and its interrelationships [30]. This component provides a unified and single view of the data of an organization.

Data organization classifies data into the key knowledge components such as knowwhat, know-who, know-how, and know-why, as well as the context-related knowledge components such as know-with, know-when, and know-where components. Context is considered as a subset of information related to different knowledge components to represent a business situation [31].

Information service provides Information-as-a-Service related to information linked to a particular context requested by business users via the Information provider API or directly via the user interface of the system.

\subsection{Knowledge-as-a-Service}

Knowledge-as-a-Service aims at the density, which refers to the recombination of resources mobilized for a particular context to overcome a business situation. This level includes the components such as knowledge discovery, decision-support, and knowledge service.

Knowledge discovery focuses on the process of applying data mining methods for knowledge discovery [32]. Knowledge discovery is defined as the process to extract knowledge from information through the application of analytic techniques to interpret the meaning of information [33].

Decision-support supports complex decision-making and problem-solving by accessing different data and information from internal and external sources, modelling data using data mining algorithms, and providing interactive queries, reporting, and graphing functions [34].

Knowledge service provides Knowledge-as-a Service to deliver different knowledge to business users, who need to find an answer to a specific business question by using the system interface or via the Knowledge provider API.

\subsection{Insight-as-a-Service}

Insight-as-a-Service focuses on the process of applying artificial intelligence (AI) applications in the business context in order to provide context-aware smart services, which are capable of actively adapting and responding based on the circumstance of interests [31]. This level includes the components such as context reasoning, context recognizing, and insight service.

Context recognizing identifies the context based on the business situation of the requested service [22]. In some specific cases, the component needs to determine users' real-time contextual information to provide suitable context-aware services.

Context reasoning understands specifically the situation, along with how it fits the overall business context, and then determines the corresponding knowledge related to the similar context in the knowledge base [22]

Insight service provides Insight-as-a-Service supported by AI-based applications such as chatbots, recommender systems, and insight engines [35]. 


\section{A Recommender system for a cultural organisation}

In order to demonstrate the proposed approach, this section presents a case study about a knowledge-based smart service system for a cultural organization, which provides recommendations as a service. The selected cultural organisation, which is indeed a privileged interlocutor of the regional cultural community that supports the development of arts and culture in Quebec, Canada. This organisation has more than 400 members who are professional artists and cultural organizations/enterprises in the local region.

Nowadays, recommender systems have been proven as a means for enterprises to increase customer satisfaction, maintain long-term relationships, and improve financial performance [36]. However, it is challenging to design, develop, and deploy AI-based solutions as a recommendation service, especially for small and medium-sized enterprises (SMEs) due to the constraint of data available and limited resources [37]. SMEs face the challenge of the cold start, which is defined as the insufficient amount of data input for the development of recommendation services [35]. Cold start also includes the challenge of making recommendations for new items, new users, and new communities $[38,39]$.

\subsection{Data-as-a-Service}

Data loading, data ingestion, and data repository. Through the process of data loading, data ingestion, and data repository, data are categorized into demographic, behavioural, transactional, and psychographic data. Demographic data contain data related to age, gender, profession, location, income, and marital status of customers [40,41]. Behavioral data are the collection of customer behaviors through their interactions with enterprises and products on websites, social media, and mobile devices $[42,43]$. Examples of behavioral data are clickstream data, add-to-favorites, add-to-cart data $[1,44]$. Transactional data involve historical purchases with related data on purchased items, amount, frequency, payment methods [44,40]. Finally, psychographic data examine customer emotions, lifestyles, and preferences $[45,46]$ to uncover purchasing motivations and satisfaction [47].

Data service. In terms of data as a service, users can create, import, and export data for different purposes. Fig. 2 demonstrates the interface and functionality of Data-as-a-Service of the recommender system developed through the Django platform. The Data-as-a-Service unblocks the limitation of business users without information technology background to work directly with data. In this light, business users can update, delete, import, and export data for specific purposes. Furthermore, business users can generate Restful API (Application Programming Interfaces) that contain data related to items (transactional data), customers (demographic data), or web activities (behavioral data). 


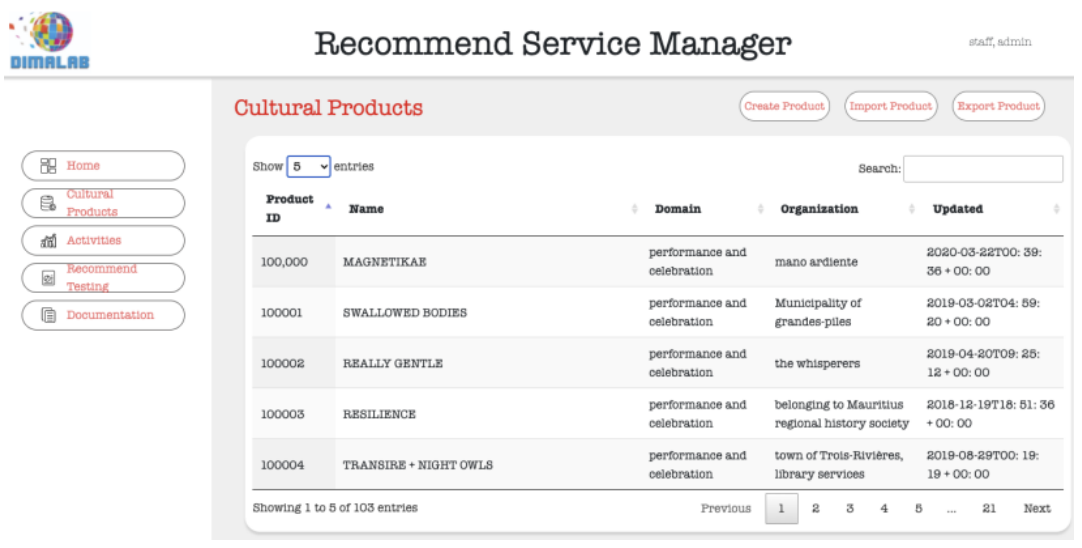

Fig. 2. Data-as-a-Service.

\subsection{Information-as-a-Service}

Data organization. Data is organized based on various business focuses at the information level in order to facilitate information as a service. Each business focus corresponds with specific types of data and knowledge components, including products and services, customers, and business activities. For example, the know-what component is derived from transactional data and touches upon the perspective of products and services. Table 1 explains in detail the business information extracted from data sources based on the business focus of the recommender system.

Table 1. Business focusses on the information level.

\begin{tabular}{|l|l|l|l|}
\hline \multicolumn{1}{|c|}{$\begin{array}{c}\text { Business } \\
\text { Focus }\end{array}$} & \multicolumn{1}{|c|}{ Related data } & \multicolumn{1}{|c|}{$\begin{array}{c}\text { Knowledge } \\
\text { components }\end{array}$} & \multicolumn{1}{c|}{ Description } \\
\hline $\begin{array}{l}\text { Products and } \\
\text { services }\end{array}$ & $\begin{array}{l}\text { Transactional } \\
\text { data }\end{array}$ & Know-what & $\begin{array}{l}\text { Declarative information that describes } \\
\text { products or services that are purchased. }\end{array}$ \\
\hline Customers & $\begin{array}{l}\text { Demographic } \\
\text { data }\end{array}$ & Know-who & $\begin{array}{l}\text { Know-who refers to customers or users who } \\
\text { interact on the website or social media. }\end{array}$ \\
\hline $\begin{array}{l}\text { Products and } \\
\text { services }\end{array}$ & $\begin{array}{l}\text { Transactional } \\
\text { data }\end{array}$ & Know-with & $\begin{array}{l}\text { Relational information that describes the } \\
\text { interrelations among products and services } \\
\text { that are purchased all together. }\end{array}$ \\
\hline $\begin{array}{l}\text { Business } \\
\text { activities }\end{array}$ & $\begin{array}{l}\text { Psychographic } \\
\text { data }\end{array}$ & Know-when & $\begin{array}{l}\text { Conditional information that describes when a } \\
\text { product or service may be purchased }\end{array}$ \\
\hline $\begin{array}{l}\text { Business } \\
\text { activities }\end{array}$ & Behavioral data & Know-where & $\begin{array}{l}\text { Situational information that describes where a } \\
\text { product or service may be purchased }\end{array}$ \\
\hline
\end{tabular}

Data integration. Through database management systems, business users can retrieve any information related to the business focus using specific database queries and semantic search [48]. In detail, with the integration of information processing, users can enquire questions to retrieve different categories of data in a section for different semantics. These queries can capture several linked, integrated, and semantic information through connected data in the databases [26].

Information service. From the perspective of information as a service, business users can pull out any information for the sake of different business focuses. For example, business users can make a query on a particular product and the information as a service will return with information of customers and business activities related to that product. From the focus on customers, business users can call information on a customer 
corresponding with their purchased products/services and business activities. Similarly, a query on business activities can link a web activity with customers and products/services.

\subsection{Knowledge-as-a-Service}

Knowledge discovery. With an aim to facilitate recommendation services, knowledge discovery uncovers the interrelationships between users and users, users and products, products and products. Accordingly, a wide variety of analytic techniques is applied to discover the knowledge of products and users [28,37]. To explore the interrelationship among users, clustering techniques are often applied to group customers into homogenous groups and develop into customer profiles. The most common clustering mining techniques are K-means, the Naïve Bayes technique, RFM analysis (recency, frequency, monetary), market basket analysis, neural networks, and self-organizing map techniques $[1,40]$. Clustering techniques divide customers into segments with similar purchase behaviours; therefore, these segments tend to assume similar products/services. This facilitates the process of recommendation as well as improves the recommendation quality.

Decision-support. To find out the interrelationships among users-products or productsproducts, association techniques are applied to examine the relationships among products/services that customers purchase; thus, enterprises can determine products that tend to be sold together [3]. Association techniques are association rules, statistics, and apriori algorithms. In addition to association, sequence discovery, which covers statistics and set theory, is used to identify associations or describe orders of behaviours over time $[47,41]$. Sequence discovery and association are techniques that stimulate cross-selling and market basket analysis to improve the extent that users satisfy with recommended products/services analysis [49]. While the cross-selling tactic is used for inducing customers to purchase related or complementary products, market basket analysis focuses on increasing the frequency and value of customer transactions through understanding their shopping habits and purchase trends [28,37].

Knowledge service. Based on the knowledge discovery, Table 2 summarizes relevant services that can be acquired from knowledge-as-a-service corresponding with information components and data mining methods. From the standpoint of recommender systems, the paper identifies the most relevant services that make use of Knowledge-as-a-Service, including general knowledge, knowledge for a specific item, and knowledge for a specific segment. Each service corresponds to business questions that are often raised by business users.

Table 2. Knowledge-as-a-Service.

\begin{tabular}{|l|l|l|l|}
\hline $\begin{array}{l}\text { Knowledge-as-a- } \\
\text { Service }\end{array}$ & Business Questions & $\begin{array}{l}\text { Knowledge } \\
\text { Components }\end{array}$ & $\begin{array}{l}\text { Data mining } \\
\text { methods }\end{array}$ \\
\hline $\begin{array}{l}\text { General } \\
\text { knowledge }\end{array}$ & $\begin{array}{l}\text { What products/services can be } \\
\text { combined altogether? }\end{array}$ & $\begin{array}{l}\text { Know-who, know- } \\
\text { what know-with, } \\
\text { know-when }\end{array}$ & $\begin{array}{l}\text { Association, } \\
\text { Prediction, } \\
\text { Classification }\end{array}$ \\
\hline $\begin{array}{l}\text { Knowledge for a } \\
\text { specific } \\
\text { product/service }\end{array}$ & $\begin{array}{l}\text { What to recommend before and } \\
\text { after the consumption of a specific } \\
\text { product/service? }\end{array}$ & $\begin{array}{l}\text { Know-who, know- } \\
\text { what know-with, } \\
\text { know-when, know- } \\
\text { where }\end{array}$ & $\begin{array}{l}\text { Association, } \\
\text { Prediction, } \\
\text { Classification }\end{array}$ \\
\hline $\begin{array}{l}\text { Knowledge for a } \\
\text { specific segment }\end{array}$ & $\begin{array}{l}\text { Which customer segments are } \\
\text { likely to purchase what } \\
\text { products/services? }\end{array}$ & $\begin{array}{l}\text { Know-who, } \\
\text { know-what }\end{array}$ & $\begin{array}{l}\text { Clustering, } \\
\text { Classification, } \\
\text { Association }\end{array}$ \\
\hline
\end{tabular}

General knowledge as Knowledge-as-a-Service. Considering the limited data sources and analytic capabilities of SMEs, the paper highlights the importance of knowledge 
discovery in proposing the most optimal recommendations by dealing with the cold start in developing recommender systems.

Literature acknowledges a wide variety of analytic techniques for recommendation solutions [3,36]. Classification methods, including k-Nearest neighbor $(\mathrm{k}-\mathrm{NN})$, decision trees, and Naïve Bayesian classifier are often applied to make recommendation decisions $[2,39]$. However, these classification methods require preference ratings of users, which is a challenge for SMEs $[38,3]$. Dealing with this challenge, the paper relies on the association method, in particular, the Apriori algorithm, to mine rules and makes the most accurate recommendation decisions $[39,36]$.

This case study simulates a data set of customers from a cultural organization. To illustrate, the Apriori algorithm is applied to a transaction dataset of events, which is acquired from ticket systems. The Apriori algorithm can mine these transactional data and figure out top rules for recommendations. The top 10 rules are illustrated in Fig. 3. As can be seen from Fig. 3, the support indicates the popularity of a set of events whereas the confidence shows the co-occurrence of all events in a rule. Accordingly, the first rule is that $85 \%$ of the customers who have no idea are likely to buy the event \{dragao [32]. The second rule is that $100 \%$ of the customers who bought the event \{alexander poulin\} are likely to buy the event $\{$ dragao $\}$.
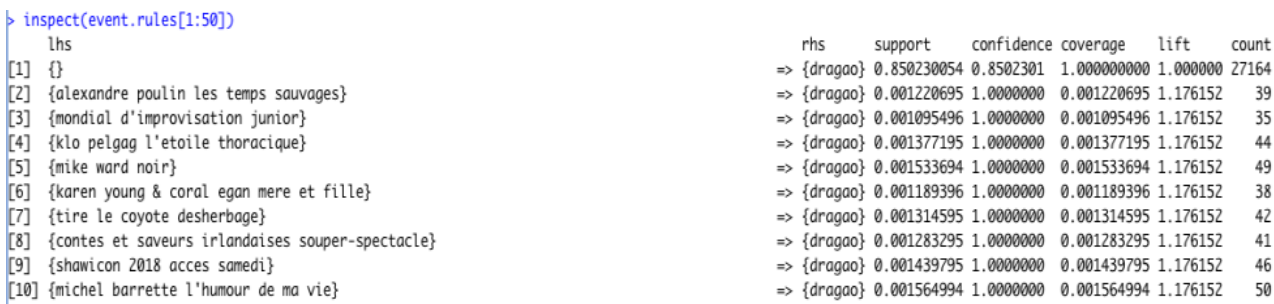

Fig. 3. General knowledge as Knowledge-as-a-Service.

Knowledge for a specific product/service as Knowledge-as-a-Service. In the case that business users want to request knowledge for a specific event, they can set lhs (if part) and $r h s S$ (then part) of the rule. For example, to find what customers buy before buying dragao", business users can set default="lhs" and rhs="dragao". Fig. 4.a reveals customers tend to attend different events before \{dragao\} such as \{alan morisod\}, \{sylvain cossette\}, and so on. On the contrary, they can figure out what customers buys after seeing "dragao" by keeping "dragao" on "lhs". As seen from Fig. 4.b, after watching \{dragao\} customers seem to watch $\{$ nezha l'enfant pirate .

a) Before a specific item

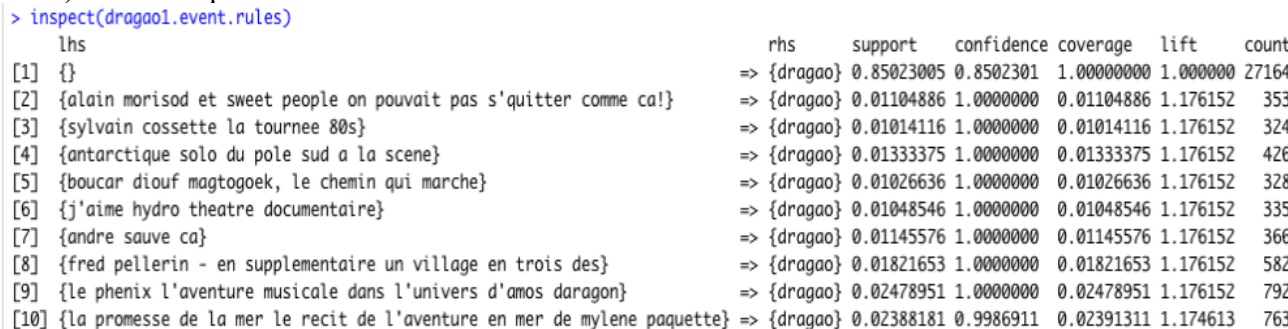

b) After a specific item

$>$ inspect(dragao.event.rules)

ths rhs support confidence coverage lift count

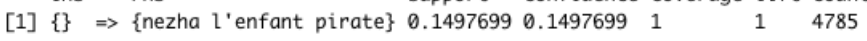

Fig. 4. Specific knowledge as Knowledge-as-a-Service. 
Knowledge for specific segments as Knowledge-as-a-Service. Due to the data constraints of SMEs, the paper suggests the association method for exploring segment associations. The Apriori algorithm is developed to generate rules related to segmentation $[38,3]$. Fig. 5 demonstrates the top 9 rules and reveals interesting findings. As can be seen from Fig. 5, lhs is the if part and rhs is the then part. As a result, these 9 rules group customers with similar characteristics into specific segments. For example, the first rule reveals that customers with low income are in the age of 19-24 and interested in humor shows. On the other hand, the 8th and 9th rules indicate that customers from 50 to 64 and with more than 3 kids seem to be keen on Mono Theatre. Furthermore, Fig. 6 displays the visualization of the different segmentations.

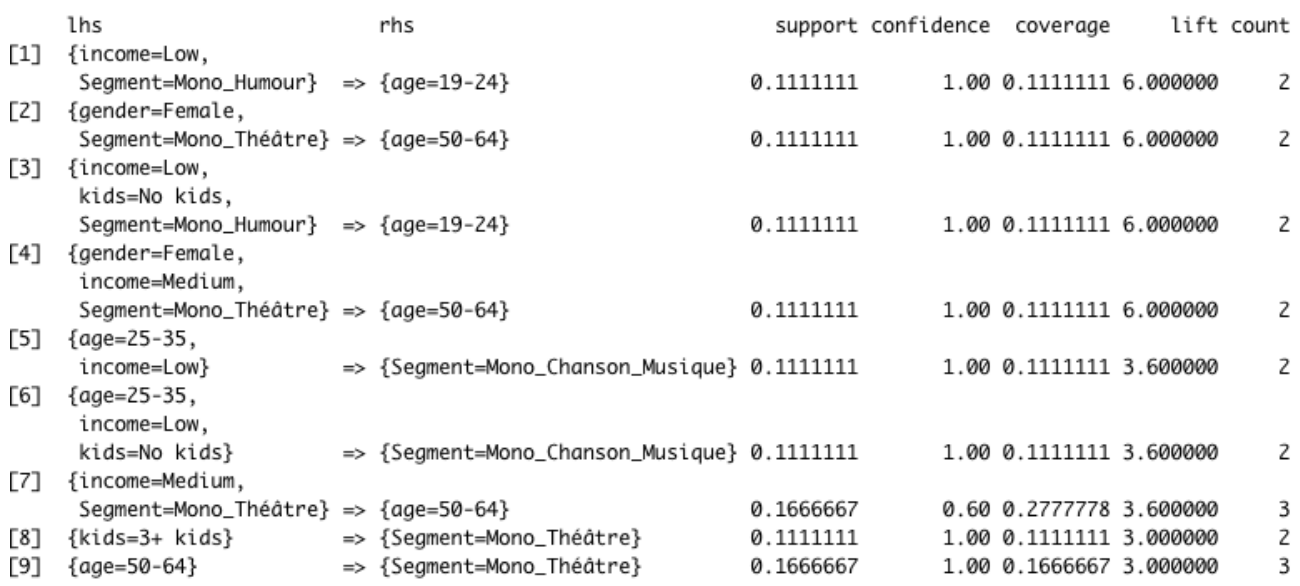

Fig. 5. Customer segmentation as Knowledge-as-a-Service.

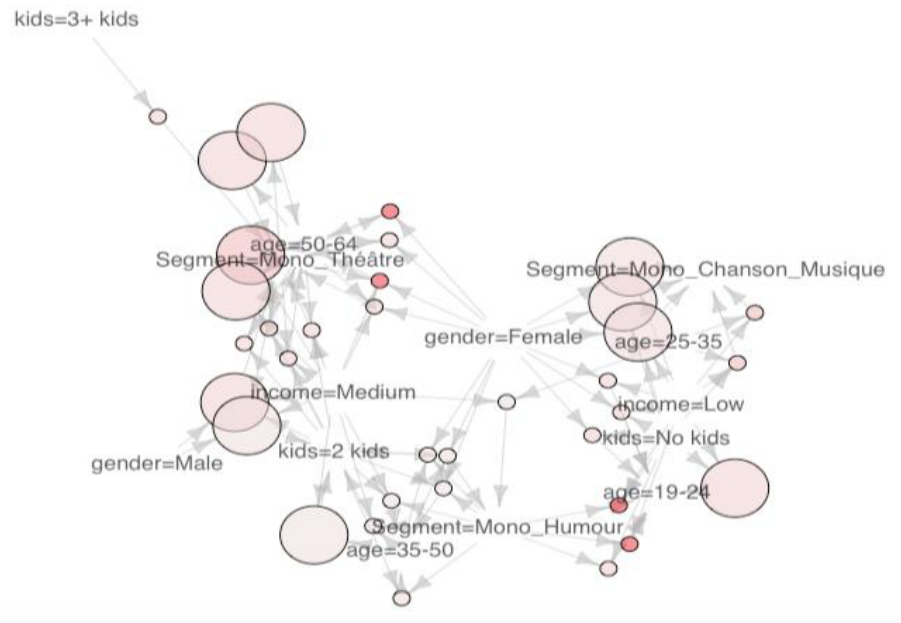

Fig. 6. Visualizing knowledge for specific segments.

\subsection{Insight-as-a-Service}

Context recognizing. Based on the information-as-a-service, recommendations are developed as a service for enterprises to implement on their website. Accordingly, Restful API (Application Programming Interfaces are generated to be embedded on the website. Furthermore, business users can set the parameters, which determine the number of 
products the system needs to return. When a business user uses the service, the information related to his identification, location, and time frame is captured to determine the use context.

Context reasoning. Each recommender API returns a list of recommended cultural products. The use context is used to customize the proposed recommendations according to the understanding of the situation, along with how it fits in the knowledge base.

Insight service. This component provides the recommender APIs based on three types of recommendations: i) Upcoming events, ii) Most popular cultural products, and iii) Similar cultural products. These recommendations are developed different mining techniques that are presented in the knowledge-as-a-service section.

Upcoming events as Insight-as-a-Service. Fig. 7 illustrates the interface of the recommender API for upcoming events. There is no input required for this API. Business users can set the number of upcoming events that the system will return. The specifications of this API are summarized as follows.

API: $\{$ host_name\}/dimadb/api/upcoming-events

Request Method: GET

Permission: Anyone who is either authenticated or not can only read the response from this API request.

Input: There is no input available for this API.

Return: A list of products where each instance is of type Event as recommendations for upcoming events

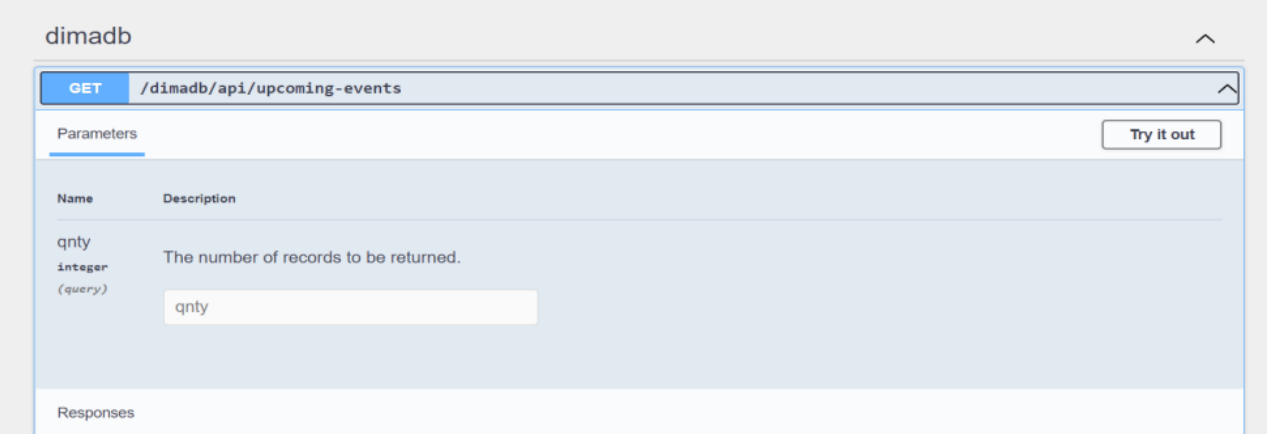

Fig. 7. Upcoming events recommender API.

Similar products as Insight-as-a-Service. Fig. 8 illustrates the interface of the recommender API for similar products. In terms of customization, business users can choose any products and determine the number of similar products the system returns as recommendations. The specifications of this API are summarized as follows.

API: $\{$ host_name\}/dimadb/api/similar-products

Request Method: GET

Permission: Anyone who is either authenticated or not can only read the response from this API request.

Input: ID of a cultural product.

Return: A list of products where each instance is of type cultural products as recommendations for similar products. 


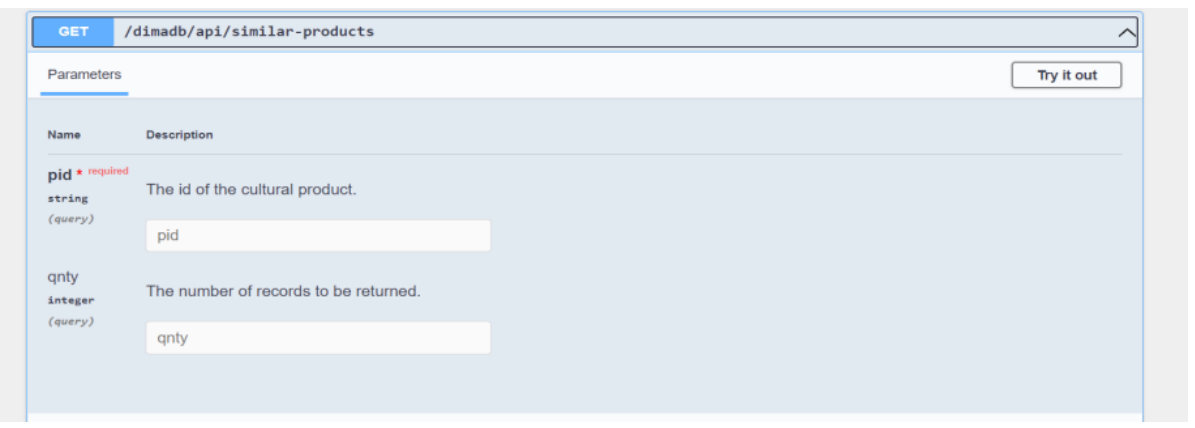

Fig. 8. Similar products recommender API.

Popular products as Insight-as-a-Service. Fig. 9 illustrates the interface of the recommender API for popular products. In terms of customization, business users can choose any products and determine the number of similar products the system returns as recommendations. The specifications of this API are summarized as follows.

API: $\{$ host_name\}/dimadb/api/popular-products

Return: A list of recommendations where each instance is of type CulturalProduct.

Request Method: GET

Permission: Anyone who is either authenticated or not can only read the response from this API request.

Input: There is no input available for this API.

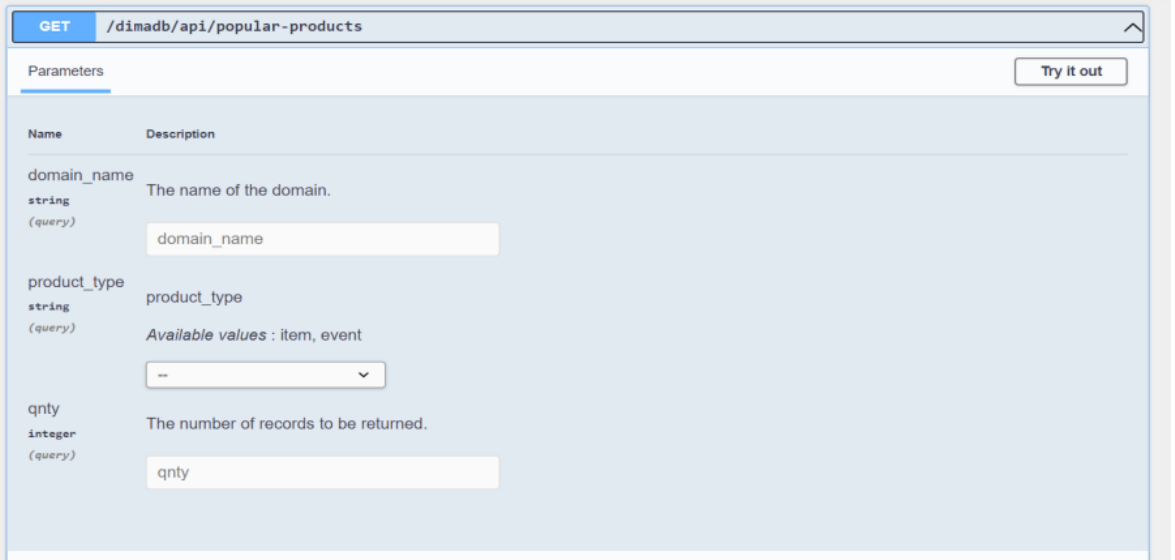

Fig. 9. Popular products recommender API.

\section{Conclusion}

In the era of big data analytics, data becomes a new source for service innovation, especially for creating context-aware smart services. The paper presents an approach for elaborating a knowledge-based smart service system, which is based on different layers of knowledge development such as Data-as-a-Service, Information-as-a-Service, Knowledgeas-a-Service, and Insight-as-a-Service. According to our knowledge, this approach is one of the first approaches that focuses on the design and implementation of a service system based on the knowledge development perspective.

Concerning the implications for research, our approach aims at adding more business value from big data and AI-based applications to transform enterprises into data-driven 
organizations. The approach helps data-driven organizations to build a new generation of smart service systems that supports the knowledge development process and provides different levels of services to facilitate service innovation.

The proposed approach has been validated and experimented with a recommender system developed for a cultural sector in Canada. Currently, an ongoing project is being carried out to develop an open-source customer intelligence system for strengthening customer relationships and is experimenting with some selected SMEs. In that case, it is foreseen that the other design science evaluations will be carried out such as optimization and dynamic analysis to evaluate the efficacy of the architecture in the future. Furthermore, our future research also focuses on the interoperability of service systems to create a coordination-ready service system based on different layers of services [50].

\section{References}

1. H. Chen, R. H. L. Chiang, V. C. Storey, Business intelligence and analytics: From big data to big impact. MIS Quarterly 36, 1165-1188 (2012)

2. K. Kesorn, W. Juraphanthong, A. Salaiwarakul, Personalized attraction recommendation system for tourists through check-in data. IEEE access 5, 26703-26721 (2017)

3. Y. Yin, L. Chen, J. Wan, Location-aware service recommendation with enhanced probabilistic matrix factorization. IEEE Access 6, 62815-62825 (2018)

4. A. Chianese, F. Piccialli, A smart system to manage the context evolution in the Cultural Heritage domain. Computers Electrical Engineering 55, 27-38 (2016)

5. C. Lim, P. P. Maglio, Data-driven understanding of smart service systems through text mining. Service Science 10(2), 154-180 (2018)

6. A. Medina-Borja, Editorial Column-Smart Things as Service Providers: A Call for Convergence of Disciplines to Build a Research Agenda for the Service Systems of the Future. Service Science 7(1), ii-v (2015)

7. D. Beverungen, M. Matzner, C. Janiesch: Information systems for smart services. In. Springer, (2017)

8. J. C. Spohrer, H. Demirkan, Introduction to the smart service systems: Analytics, cognition, and innovation minitrack. 2015 48th Hawaii International Conference on System Sciences, (IEEE, 2015)

9. D. T. Le, T. T. P. Thi, C. Pham-Nguyen, Towards a Context-Aware Knowledge Model for Smart Service Systems. International Conference on Computational Collective Intelligence, (Springer, 2020)

10. J. Annas, An introduction to Plato's Republic. (1981)

11. I. Nonaka, I. o Nonaka, N. Ikujiro, H. Takeuchi, The knowledge-creating company: How Japanese companies create the dynamics of innovation, vol. 105. OUP USA, (1995)

12. M. Abzari, M. Shojaei, B. Forouzan, Designing of conceptual model of motivation in knowledge management implementation case study: Gas company in Isfahan province. European Journal of Economics, Finance and Administrative Sciences 45, 26-38 (2012)

13. T. Le Dinh, L. Rinfret, L. Raymond, B. T. D. Thi, Towards the reconciliation of knowledge management and e-collaboration systems. Interactive Technology and Smart Education (2013)

14. R. Garud, On the distinction between know-how, know-what, and know-why. Advances in strategic management 14, 81-102 (1997)

15. T. Le Dinh, T. H. Van, T. S. Nomo, A framework for knowledge management in project management offices. The Journal of Modern Project Management 3(3) (2016)

16. H. Cleveland, Information as a resource. Futurist 16(6), 34-39 (1982) 
17. J. Manyika, M. Chui, B. Brown, J. Bughin, R. Dobbs, C. Roxburgh, A. Hung Byers, Big data: The next frontier for innovation, competition, and productivity. McKinsey Global Institute, (2011)

18. S. Batra, Big data analytics and its reflections on DIKW hierarchy. Review of Management 4(1/2), 5 (2014)

19. K. C. Laszlo, A. Laszlo, Evolving knowledge for development: the role of knowledge management in a changing world. Journal of Knowledge Management (2002)

20. J. Rowley, The wisdom hierarchy: representations of the DIKW hierarchy. Journal of information Science 33(2), 163-180 (2007)

21. P. P. Maglio, C.-H. Lim, Innovation and big data in smart service systems. Journal of Innovation Management 4(1), 11-21 (2016)

22. T. L. Dinh, N. A. K. Dam, Towards Smart Customer Knowledge Management Systems. International Conference on Computational Collective Intelligence, (Springer, 2021)

23. C.-H. Lim, K.-J. Kim, IT-enabled information-intensive services. IT Professional 17(2), 26-32 (2015)

24. A. Intezari, S. Gressel, Information and reformation in KM systems: big data and strategic decision-making. Journal of Knowledge Management 21(1), 71-91 (2017)

25. J. R. Vest, S. J. Grannis, D. P. Haut, P. K. Halverson, N. Menachemi, Using structured and unstructured data to identify patients' need for services that address the social determinants of health. International journal of medical informatics 107, 101-106 (2017)

26. T. Le Dinh, T.-C. Phan, T. Bui, M. C. Vu, Towards a Service-Oriented Architecture for Knowledge Management in Big Data Era. International Journal of Intelligent Information Technologies 14(4), 24-38 (2018)

27. P. Bellini, P. Nesi, M. Paolucci, I. Zaza, Smart city architecture for data ingestion and analytics: Processes and solutions. 2018 IEEE Fourth International Conference on Big Data Computing Service and Applications (BigDataService), (IEEE, 2018)

28. P. Mikalef, J. Krogstie, I. O. Pappas, P. Pavlou, Exploring the relationship between big data analytics capability and competitive performance: The mediating roles of dynamic and operational capabilities. Information \& Management 57(2), 103169 (2020)

29. T. Le Dinh, N. A. K. Dam, Smart data as a service. Proceedings of the International conference on exploring service science (IESS) 2.1, (2021)

30. T. Le Dinh, T. H. Le, Towards an Approach for Modeling Interoperability of Information Systems. 2007 IEEE International Conference on Research, Innovation and Vision for the Future, (IEEE, 2007)

31. D. T. Le, T. T. P. Thi, C. Pham-Nguyen, L. N. H. Nam, Towards a context-aware knowledge model for smart service systems. International Conference on Computational Collective Intelligence, (Springer, 2020)

32. M. Alavi, D. E. Leidner, Knowledge management and knowledge management systems: Conceptual foundations and research issues. MIS Quarterly, 107-136 (2001)

33. E. Begoli, J. Horey, Design principles for effective knowledge discovery from big data. 2012 Joint Working IEEE/IFIP Conference on Software Architecture and European Conference on Software Architecture, (IEEE, 2012)

34. J. P. Shim, M. Warkentin, J. F. Courtney, D. J. Power, R. Sharda, C. Carlsson, Past, present, and future of decision support technology. Decision support systems 33(2), 111 $126(2002)$

35. N. A. K. Dam, T. Le Dinh, W. Menvielle, Towards a Conceptual Framework for Customer Intelligence in the Era of Big Data. International Journal of Intelligent Information Technologies (IJIIT) 17(4), 1-17 (2021)

36. N. A. K. Dam, T. Le Dinh: A Literature Review of Recommender Systems for the Cultural Sector. Paper presented at the Proceedings of the 22nd International Conference on Enterprise Information, Czech Republic, 
37. J. R. Saura, D. Palacios-Marqués, D. Ribeiro-Soriano, Digital marketing in SMEs via data-driven strategies: Reviewing the current state of research. Journal of Small Business Management, 1-36 (2021)

38. J. Borràs, A. Moreno, A. Valls, Intelligent tourism recommender systems: A survey. Expert Systems with Applications 41(16), 7370-7389 (2014)

39. N. M. Villegas, C. Sánchez, J. Díaz-Cely, G. Tamura, Characterizing context-aware recommender systems: A systematic literature review. Knowledge-Based Systems 140, 173-200 (2018)

40. S. Erevelles, N. Fukawa, L. Swayne, Big Data consumer analytics and the transformation of marketing. Journal of Business Research 69(2), 897-904 (2016)

41. S. L. France, S. Ghose, Marketing analytics: Methods, practice, implementation, and links to other fields. Expert Systems with Applications 119, 456-475 (2018)

42. A. Rawson, E. Duncan, C. Jones, The Truth About Customer Experience. Harvard Business Review (2013)

43. N. A. K. Dam, T. Le Dinh, W. Menvielle, A Service-based Model for Customer Intelligence in the Age of Big Data. Proceedings of Americas Conference on Information Systems 9 (2020)

44. S. Fan, R. Y. K. Lau, J. L. Zhao, Demystifying Big Data Analytics for Business Intelligence Through the Lens of Marketing Mix. Big Data Research 2(1), 28-32 (2015)

45. M. Holmlund, Y. Van Vaerenbergh, R. Ciuchita, A. Ravald, P. Sarantopoulos, F. V. Ordenes, M. Zaki, Customer experience management in the age of big data analytics: A strategic framework. Journal of Business Research (2020)

46. D. Lafrenière, Digital transformation: start with the customer, not IT! Les Affaires (2020)

47. T. Hong, E. Kim, Segmenting customers in online stores based on factors that affect the customer's intention to purchase. Expert Systems with Applications 39(2), 2127-2131 (2012)

48. S. Galhotra, U. Khurana, Semantic Search over Structured Data. Proceedings of the 29th ACM International Conference on Information \& Knowledge Management, (2020)

49. N. A. K. Dam, T. Le Dinh, W. Menvielle, Marketing Intelligence From Data Mining Perspective - A Literature Review. International Journal of Innovation, Management and Technology (2019)

50. T. Le Dinh, M. Léonard, Towards coordination-ready information systems: the Information System Component approach. Proceeding of AISTA, Luxembourg (2004) 